\title{
CORRESPONDENCE
}

\section{VON GRAEFE versus KERATOME}

To the Editorial Committee of the

British JOURnAl. OF Ophthalmologil

Diar Sirs In his article, Keratome and Scissors, Mr. A. H. Osmond* fires another shot in the battle between the use of the von Graefe knife and the keratome in cataract extraction.

The advantages of keratome and scissors were amplified ably by Mr. Castroviejoi, and the theoretical advantages are as great as the practical advantage that the surgeon knows that the eye has been thoroughly sutured, especially when the nursing is not in the hands of those specially trained.

There are, however, two disadvantages to the method which need to be stressed. After a conjunctival flap (even one as small as $2 \mathrm{~mm}$.) has been fashioned, it is not easy to see the tip of the keratome when it enters the anterior chamber. The tendency is to depress the handle of the instrument too soon and so to make an oblique cut producing a corneal lip which interferes with delivery of the lens. Secondly, it is not easy to watch the blade of the scissors which is within the anterior chamber, because it also is behind the conjunctival flap, and the root of the iris may be cut inadvertently.

My early cases took, from start to finish, one hour instead of about twenty minutes, but, although the first one of all resulted in an acuity of $6 / 6$ and Jaeger 1 , the fact that $I$ had to use the vectis in two cases, because of an oblique incision, caused me to discard the method.

During some three years at Moorfields I watched some of our best surgeons extract a very large number of cataracts with the von Graefe knife, and although I think that I saw every complication that could occur, I cannot remember having seen any trouble arising from the incision itself.

In my own small experience, I have encountered infection, iridocyclitis, glaucoma, and haemorrhage as complications, but recovery has been the rule. No complications have arisen because: of

Osmond, A. H. (1951). British Journal of Ophthalmology, 35, 406.

+ Castroviejo, R. (1948). In "Modern Trends in Ophthalmology", ed. A. Sorsby, vol. 2, pp. 449-468. Butterworth, London. 
indifferent incisions, and in two cases where the iris rose above the knife, the complete iridectomies followed the normal course during convalescence.

In assessing the relative merits of the two methods of extraction one must consider two factors: (a) the von Graefe method is simple and quick, and has withstood the test of time and usage in many thousands of cases: its drawbacks are known and its complications understood; (b) the keratome and scissors method, though theoretically preferable, is complicated and takes longer; yet it results in a completely sutured eye which follows normal surgical procedure.

With regard to the instruments introduced into the eye, more than two must be used whichever method is employed; the number of instruments should not cause either method to be condemned, and the sharpness of knife or keratome can be no criterion, for before the eye is entered one feels whether the point is satisfactory or not, and it is simple to take another from the instrument rack.

The experienced surgeon will be slow to drop a method which has given excellent results in his hands: the tyro will adopt the method on which he is brought up: the indifferent surgeon will remain indifferent whatever technique he attempts.

The whole subject, with an emphasis on those cases which go wrong, would form an excellent topic for a major item at one of our Congresses; it is of sufficient importance to warrant a thorough discussion " at the highest level ".

Yours faithfully,

Frank R. Neubert.

Hauterive, The Queen's Road,

GUERNSEY. July 10, 1951.

\section{SIGHT OF UNDERGRADUATES}

\section{To the Editorial Committee of the}

\section{BRITISH JourNal OF OPHTHALMOLOGY}

DeAR SIRS-The author of the paper entitled Sight of Undergraduates (British Journal of Ophthalmology, 35, 467) includes in his summary a statement that " the sight of undergraduates is four times worse than that of 18-year-old men in the general population ", but no such conclusion can be drawn from the facts presented. The author's Table IV certainly shows that his sample of undergraduates contained rather more than four times as many poor-sighted persons as would be expected among a 